\title{
Leadership \& Professional Development: Cultivating Habits for the Hospitalist
}

\author{
Sri Lekha Tummalapalli, MD, MBA*
}

Division of Nephrology, Department of Medicine, University of California, San Francisco, California.

"We are what we repeatedly do. Excellence, then, is not an act, but a habit."

-Will Durant

We are a collection of our habits - the routine, repetitive, subconscious behaviors we perform on a daily basis. Some of these behaviors are positive, others less so. Habits allow us to perform tasks automatically, without the need for active decision making. Amidst a constantly changing clinical environment, cultivating consistent habits can improve our adherence to best practices and free cognitive effort toward more challenging diagnostic or therapeutic tasks.

Establishing habits requires practice and intentionality. First, identify those habits that are desirable in your personal and professional life. Next, find a method to develop the habit. Then, hold yourself accountable as you work to embed the habit. Simple? Not quite.

In "The Power of Habit," author Charles Duhigg introduces habit loops as a way to successfully develop this practice. ${ }^{1}$ Habit loops-sequences comprising a cue, routine, and reward-are integral to developing routines that support professional and personal aspects of hospitalist life. Consider a hospitalist seeking to develop a prerounds routine to increase efficiency and limit missed patient information. First, the clinician should identify a cue to start the routine, such as sitting down to log in at a specific workstation. Second, a sequence of actions is "chunked" into a consistent order, such as a review of vital signs, clinical notes, and patient labs. After the routine is completed, the clinician should finish with a reward, such as a cup of coffee after rounds. Want to set up a habit for ensuring learning goals are set with trainees at the beginning of every block? Set a calendar reminder for this on the first day, standardize how you communicate goals, and reward yourself with a team lunch at the end of the rotation. What if it's a busy first day on service? Doesn't

*Corresponding Author: Sri Lekha Tummalapalli, MD, MBA; E-mail: srilekha. tummalapalli@ucsf.edu; Telephone: 415-476-1812

Received: June 25, 2019; Accepted: June 26, 2019

(C) 2020 Society of Hospital Medicine DOI 10.12788/jhm.3276 matter. As Clay Christensen notes in "How Will You Measure Your Life?" making one commitment to a habit is easier than deciding whether or not to engage in the routine every time new circumstances arise. ${ }^{2}$ The intentionality that comes with this act ensures consistency in the practice.

As a busy hospitalist, establishing habits for personal and professional development requires cues and rewards. For example, do you want to cement a habit of reading the latest journal articles or carving out time each day to reflect on your work? Then cultivate the routine by creating a cue, such as a dashboard on a wall to visualize how many articles you've read this week or whether you've paused to reflect on your rotation. Reinforce the routine by creating a reward: a walk outside, time with family, or another activity you enjoy. Pair the same reward with the same routine to strengthen the habit loop.

A few additional tips for cultivating habits: it is useful to pair an existing reliable habit, or "anchor habit," with a new one, such as a short meditation after brushing your teeth. ${ }^{3}$ Doing so reinforces behaviors in a positive way. You may use the same principles to lose unwanted habits (eg, checking e-mail excessively) by removing cues, such as turning off notifications or using airplane mode and rewarding yourself when you see the behavior through.

Habits are larger than behaviors; they can impact your personal and professional life in important ways. By actively creating habits that align with your long-term priorities, you can create a safety net if and when change arrives. Understanding the psychology of habits and employing cues and rewards effectively can lead hospitalists to create positive routines that improve their clinical practice and personal lives.

Disclosures: The author has no disclosures.

Funding: No funding sources supported this work.

\section{References}

1. Duhigg C. The Power of Habit: Why We Do What We Do in Life and Business. Random House; 2012.

2. Christensen CM. How Will You Measure Your Life? (Harvard Business Review Classics). Harvard Business Review Press; 2017.

3. Fogg B. Tiny Habits w/Dr. BJ Fogg-Behavior Change: Tiny Habits; 2011. 